\title{
The PACAP Receptor: A Novel Target for Migraine Treatment
}

\author{
Henrik W. Schytz, Jes Olesen, and Messoud Ashina \\ Danish Headache Center and Department of Neurology, Glostrup Hospital, Faculty Of Health Sciences, \\ University of Copenhagen, 2600 Glostrup, Denmark
}

\begin{abstract}
Summary: The origin of migraine pain has not yet been clarified, but accumulating data point to neuropeptides present in the perivascular space of cranial vessels as important mediators of nociceptive input during migraine attacks. Pituitary adenylate cyclase-activating polypeptide (PACAP) is present in sensory trigeminal neurons and may modulate nociception at different levels of the nervous system. Human experimental studies have shown that PACAP-38 infusion induces marked dilatation of extracerebral vessels and delayed migraine-like
\end{abstract}

attacks in migraine patients. PACAP selectively activates the $\mathrm{PAC}_{1}$ receptor, which suggests a possible signaling pathway implicated in migraine pain. This review summarizes the current evidence supporting the involvement of PACAP in migraine pathophysiology and the $\mathrm{PAC}_{1}$ receptor as a possible novel target for migraine treatment. Key Words: Migraine, vasodilatation, mast-cell degranulation, trigeminal nociceptive system, human experimental headache models, drug targets.

\section{INTRODUCTION}

Migraine patients experience intense head pain during attacks, which results in disability and high socioeconomic costs. ${ }^{1}$ Thus, clinical research to discover new specific drug targets for migraine is highly needed. ${ }^{2}$ The origin of pain during migraine attacks is still not fully elucidated. Activation of peripheral trigeminal nociceptors in the perivascular space of cranial arteries probably generates input that leads to the experience of migraine pain. ${ }^{3}$ In support of this view, it has been shown that signaling molecules, such as nitric oxide (NO) and calcitonin gene-related peptide (CGRP), found in nerve fibers surrounding cranial arteries, ${ }^{4-7}$ induce migraine-like attacks indistinguishable from spontaneous migraine attacks. ${ }^{8,9}$ Pituitary adenylate cyclase activating polypeptide (PACAP) is a neuropeptide present in the perivascular space of cranial arteries. Recent studies point to the involvement of PACAP in migraine pain. ${ }^{10}$ Here we review the evidence on how PACAP might be implicated in specific receptor activation during migraine attacks and discuss how the $\mathrm{PAC}_{1}$ receptor could be a novel target for migraine treatment.

Address correspondence and reprint requests to: Messoud Ashina, Danish Headache Center and Department of Neurology, Glostrup Hospital, University of Copenhagen, Faculty of Health Sciences, Nordre Ringvej 57, 2600 Glostrup, Copenhagen, Denmark. E-mail: ashina@ dadlnet.dk.

\section{PACAP STRUCTURE, DISTRIBUTION, AND RECEPTORS}

PACAP was originally isolated in the late 1980s from an ovine hypothalamus extract on the basis of its ability to stimulate cAMP formation in rat pituitary cells. ${ }^{11}$ PACAP belongs to the vasoactive intestinal polypeptide (VIP)-secretin-growth hormone-releasing hormoneglucagon superfamily ${ }^{12}$ and is found as a 38 -amino-acid peptide (PACAP-38) and a truncated 27-amino-acid peptide (PACAP-27). PACAP-38 is the predominant peptide and represents more than $90 \%$ of the total PACAP content in most tissues, including the CNS. ${ }^{13-16}$

PACAP has been identified in human sensory ${ }^{17}$ and parasympathetic ${ }^{4}$ ganglia, as well as in second-order neurons of the trigeminal nucleus caudalis (TNC). ${ }^{18}$ The N-terminal 28 amino acids of PACAP-38 share 68\% homology with VIP, ${ }^{19}$ and the two related peptides are colocalized in rat parasympathetic ganglia. ${ }^{5,20}$

The action of PACAP is mediated through three Gprotein coupled receptors: $\mathrm{VPAC}_{1}$ and $\mathrm{VPAC}_{2}$, which have an equally high affinity for PACAP and VIP, and $\mathrm{PAC}_{1}$, which has a 1000-fold higher affinity for PACAP than for VIP. ${ }^{21}$ Activation of all three receptors increases cAMP; phospholipase C (PLC) and intracellular calcium have also been reported as effector pathways $^{22,23}$ (FIG. 1).

The messenger RNAs for all PACAP receptors have been identified in human cerebral arteries ${ }^{24}$ and in sen- 


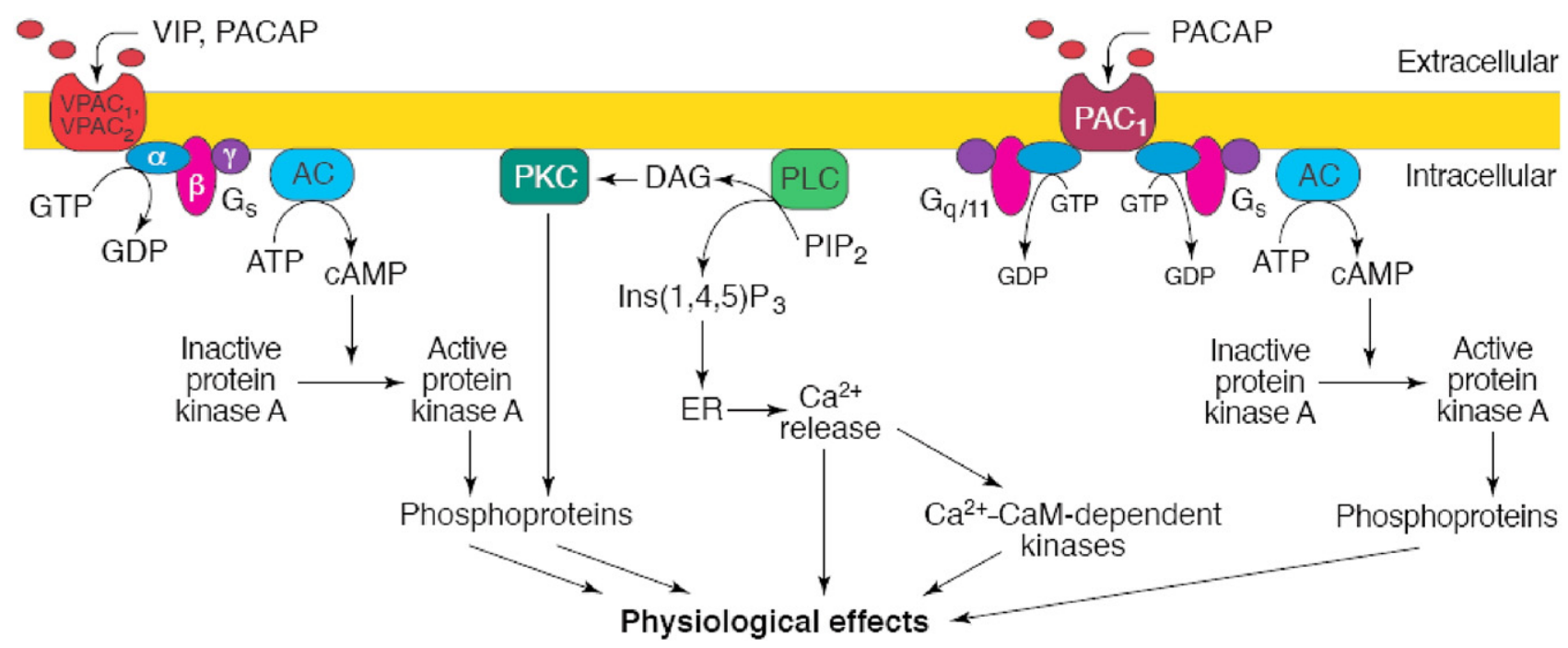

FIG. 1. Highlight of the principal intracellular signaling pathways activated by $\mathrm{VPAC}_{1}, \mathrm{VPAC}_{2}$, and $\mathrm{PAC}_{1}$ receptors. Upon activation, all three receptors are capable of causing downstream production of cAMP. In addition, the three receptors can also activate phospholipase $\mathrm{C}(\mathrm{PLC})$, leading to an increase in $\mathrm{Ca}^{2+}$. $\mathrm{AC}=$ adenylate cyclase; $\mathrm{CaM}=$ calmodulin; $\mathrm{DAG}=$ diacylglycerol; $\mathrm{ER}=$ endoplasmic reticulum; $\mathrm{G}_{\mathrm{q} / 11}=\mathrm{G}_{\mathrm{s}}$, G-family proteins; Ins $(1,4,5) \mathrm{P}_{3}=$ inositol 1,4,5-trisphosphate; PACAP = pituitary adenylate cyclase-activating polypeptide; $\mathrm{PIP}_{2}=$ phosphatidylinositol 3,4-bisphosphate; $\mathrm{PKC}=$ protein kinase $\mathrm{C} ; \mathrm{VIP}=$ vasoactive intestinal polypeptide; $\alpha, \beta, \gamma=$ subtypes of G-protein. Reproduced from Dickinson et al., ${ }^{23}$ with permission from Elsevier.

sory, parasympathetic, and sympathetic ganglia with perivascular nerve fiber projections. ${ }^{24}$

In this review we will describe the possible role of PACAP in nociceptive processing in the peripheral and central nervous system relevant for migraine pain.

\section{The peripheral actions of PACAP}

Stimulation of the superior sagittal sinus causes a 2.6fold increase in PACAP plasma concentrations in the external jugular vein in cats. ${ }^{25}$ Whether this is caused by PACAP released from trigeminal sensory or parasympathetic perivascular fibers is unknown. Human experimental studies suggest that parasympathetic activation is pronociceptive, in that migraine pain is reduced after anesthetic blocking of the parasympathetic sphenopalatine ganglion. ${ }^{26,27}$ Because parasympathetic and trigeminal fibers are closely related in the perivascular space, ${ }^{28}$ it is possible that PACAP released from either system could lead to modulation of sensory input in trigeminal neurons.

Dilatation of cranial vessels might contribute to pain during migraine attacks. ${ }^{29,30}$ PACAP-38 dilates both animal $^{31-33}$ and human ${ }^{34}$ cerebral arteries; however, only $\mathrm{VPAC}_{1}$ receptor antagonists inhibit PACAP-38-induced dilation in the rat middle cerebral artery $(\mathrm{MCA})^{35}$ and middle meningeal artery (MMA). ${ }^{33}$ In the human coronary artery, PACAP-induced dilatation is not changed by $\mathrm{PAC}_{1}$ receptor antagonism. ${ }^{36}$ These data indicate that activation of the $\mathrm{PAC}_{1}$ receptor does not contribute to extracranial or intracranial vasodilatation.

During recent years, mast cell degranulation has been suggested to be involved in migraine pathophysiology. ${ }^{37,38}$ The evidence is based primarily on studies showing that plasma histamine levels are elevated during migraine attacks in a subpopulation of migraine patients, ${ }^{39}$ and that histamine induces migraine-like attacks following intravenous infusion. ${ }^{40}$ Furthermore, mast cell degranulation causes activation of meningeal nociceptors in the rat dura mater. ${ }^{41,42} \mathrm{VPAC}_{2}$ receptors, but not $\mathrm{VPAC}_{1}$, are expressed on human mast cells ${ }^{43}$; to date, no studies have investigated the expression of $\mathrm{PAC}_{1}$ receptors on mast cells. In human skin, PACAP-38 and VIP degranulate mast cells and cause histamine release in vitro. ${ }^{44}$ VIP seems to be the more potent than PACAP-38 in degranulating mast cells in vitro. ${ }^{44}$ Furthermore, VIP releases a relatively small proportion $(10 \%)$ of histamine from human dural mast cells, compared with CGRP (10\% vs 32\%). ${ }^{45}$ Thus, it seems unlikely (although it remains to be investigated) that PACAP can induce sufficient mast cell degranulation in the perivascular space of cranial arteries to result in nociceptive input.

Stimulation of both $\mathrm{VPAC}_{1-2}$ and $\mathrm{PAC}_{1}$ receptors elevates cAMP, ${ }^{46}$ but in cultured neural cells PACAP-38 stimulates adenylate cyclase activity at least 1000 times more than VIP does. ${ }^{11}$ Thus, it is possible that PACAP via the $\mathrm{PAC}_{1}$ receptor could elevate $\mathrm{CAMP}$ in peripheral trigeminal nociceptors, resulting in nociception. In fact, animal models in both rat $^{47}$ and guinea pig ${ }^{48}$ have shown trigeminal neurons to be sensitized through elevation of cAMP. Recently, Akerman and Goadsby ${ }^{49}$ also showed that $\mathrm{VPAC}_{1}$ and $\mathrm{PAC}_{1}$ receptor inhibition blocked neuronal firing of second-order trigeminal neurons elicited by activation of the parasympathetic superior salivatory nucleus projecting to the perivascular space. Nonetheless, it has not yet been directly demonstrated if VPAC or 
$\mathrm{PAC}_{1}$ receptors mediate activation or sensitization of trigeminal nociceptors.

\section{The central actions of PACAP}

PACAP immunoreactivity is present in the human $\mathrm{TNC},{ }^{18}$ but is also found in cell bodies of the brain stem locus coeruleus, ${ }^{50}$ which projects to the $\mathrm{TNC}^{51}$ and is reported to be activated during spontaneous migraine attacks. ${ }^{52}$ Animal experimental models have proposed that PACAP might have a role in central pain transmission. ${ }^{53}$ Capsaicin elevates PACAP in rat cerebrospinal fluid in vivo ${ }^{54}$ suggesting that PACAP may be released from activated $\mathrm{C}$-fibers in the spinal cord. In PACAP gene knockout mice (Adcyap $1^{-l-}$ ), inflammatory pain disappears $^{55}$ and PACAP promotes the functional coupling of neuronal NO-synthase to NMDA receptors. This leads to NO production in superficial layers of the dorsal horn in the spinal cord ${ }^{55}$ and late-onset, transcriptionaland activity-dependent central sensitization. ${ }^{56}$ PAC $_{1}$ receptor knockout mice have a decreased response in nociceptive behavior after a formalin test, ${ }^{57}$ which is a model of inflammatory nociception. $\mathrm{PAC}_{1}$ receptor antagonism also effectively attenuated nociception in inflammatory models of pain in rats ${ }^{58}$ and mice ${ }^{59}$ after intrathecal administration. These data suggest that activation of the $\mathrm{PAC}_{1}$ receptor could lead to modulation of nociceptive input in the second-order neurons.

\section{HUMAN PACAP MODEL OF MIGRAINE}

The headache eliciting and vasodilatory effect in cranial arteries after infusion of PACAP-38 was examined in 12 healthy volunteers and 12 patients with migraine without aura in a randomized double-blind crossover study. ${ }^{10}$ PACAP-38 infusion caused headache in all 12 healthy subjects and in 11 of the 12 migraine patients. The headache peaked 4-5 hours after the end of infusion (FIG. 2). The most important finding of the study was that $58 \%$ of the migraine patients experienced migrainelike attacks after PACAP-38 infusion; most attacks occurred several hours after the end of infusion. PACAP-38 also induced pronounced dilatation of intra- and
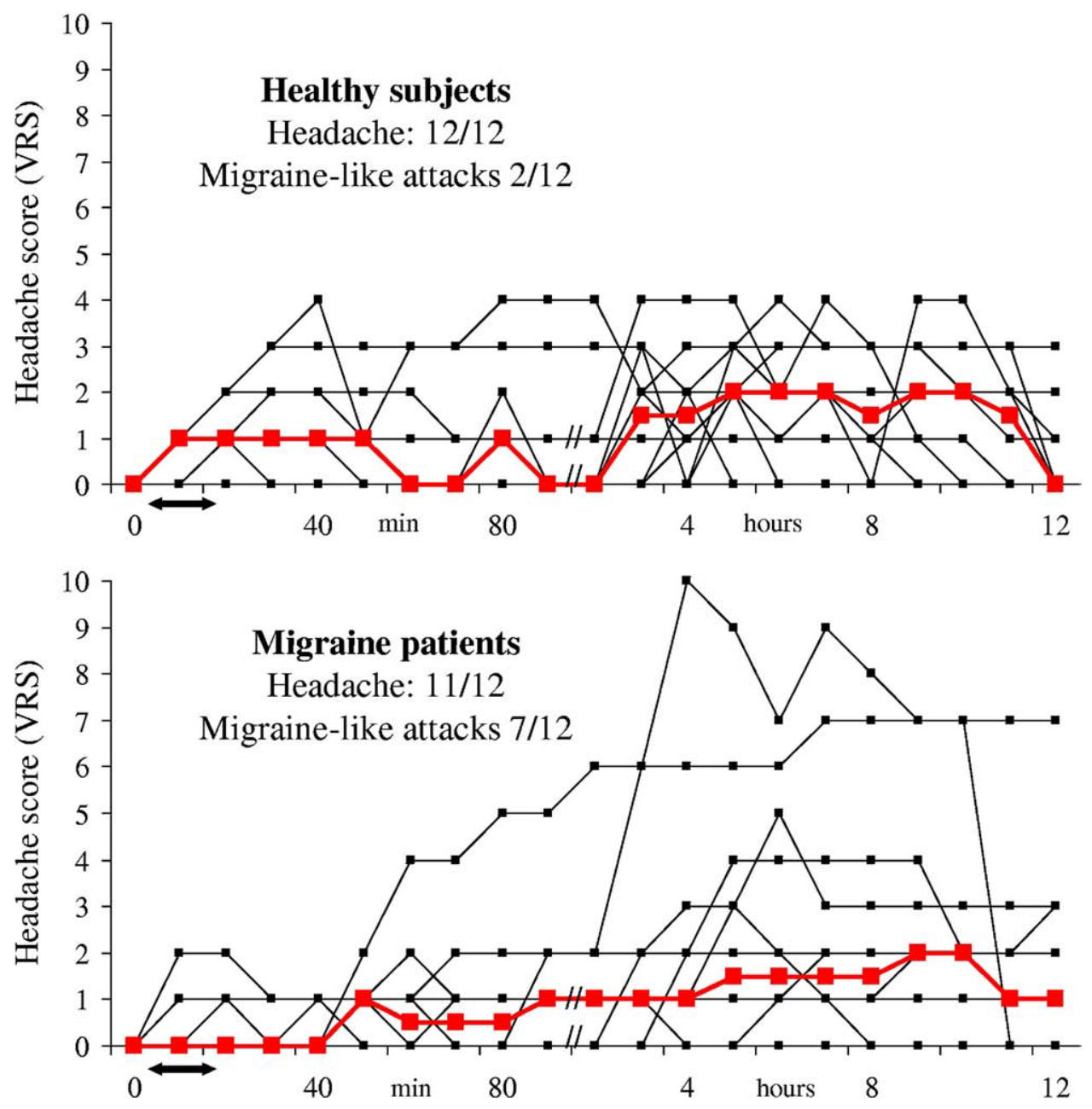

FIG. 2. Individual and median headache scores on a verbal rating scale (VRS) from time 0-90 minutes and 2-12 hours after PACAP-38 infusion in healthy subjects (top panel) and migraine patients (bottom panel). Note break in scale for time axis. Thick red lines indicate median headache scores. Double-ended arrows mark infusion time. Adapted from Schytz et al. ${ }^{10}$ with permission. 


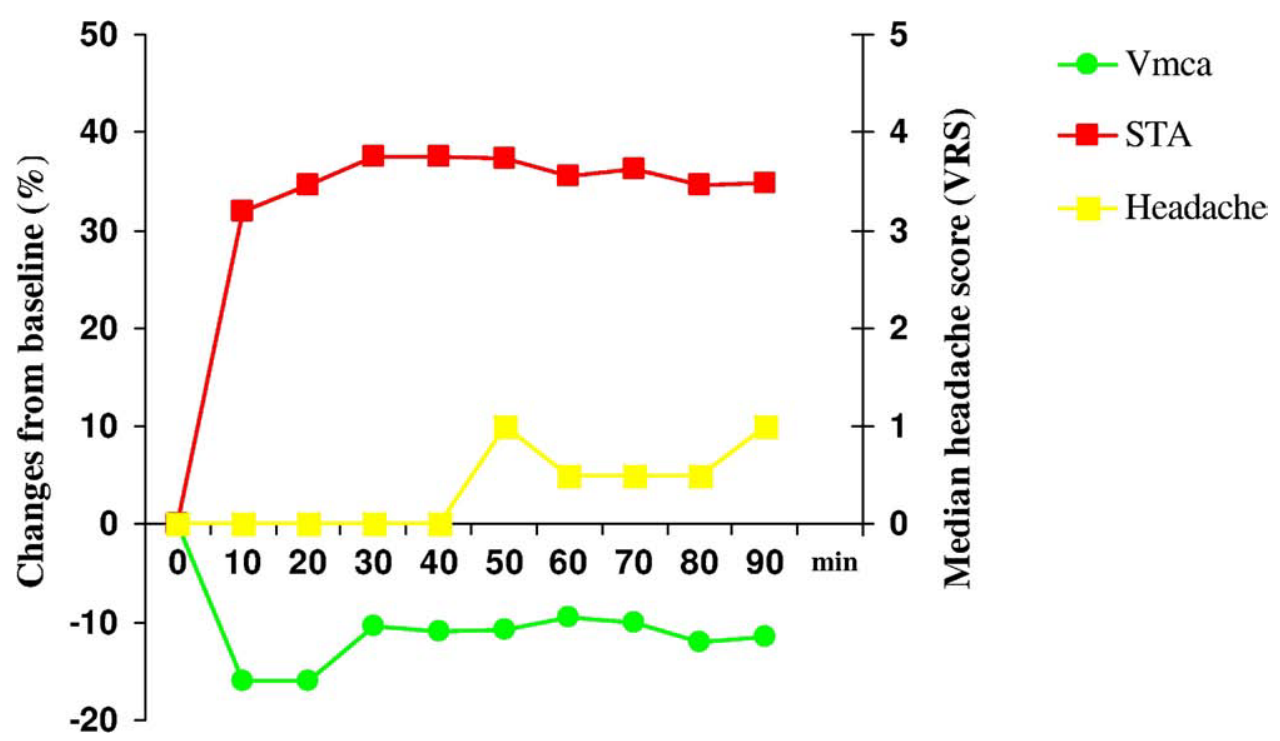

FIG. 3. Hemodynamic changes from baseline in migraine patients after PACAP-38 in comparison with median headache score on a verbal rating scale (VRS). Vmca = mean blood flow velocity in the middle cerebral artery; STA = diameter of the superficial temporal artery. Adapted from Schytz et al. ${ }^{10}$ with permission.

extracranial arteries, with maximum at 20 minutes after the start of infusion, which remained sustained throughout the 90-minute recording period (FIG. 3).

VIP, given in exactly the same quantity as PACAP-38 (200 pmol/kg), has been studied in similar studies. ${ }^{60,61}$ These studies showed that the systemic administration of VIP induces only a very mild and short-lasting immediate headache in both healthy subjects $^{60}$ and migraineurs. ${ }^{61}$ Despite marked immediate vasodilatation, no migraine sufferer reported delayed migraine-like attacks after VIP. Given that VIP infusion does not cause migraine, the shared $\mathrm{VPAC}_{1}$ and $\mathrm{VPAC}_{2}$ receptors seem unlikely to be involved in PACAP-38induced migraine. Thus, migraine induction by PACAP-38 might be caused by selective activation of the $\mathrm{PAC}_{1}$ receptor.

A recent study attempted to explore pronociceptive properties of PACAP-38 and VIP in humans, using a skin model of acute pain. ${ }^{62}$ Pain intensities after VIP and PACAP-38 were mild and limited to a short time, approximately 100 seconds after injection. VIP caused more neurogenic inflammation and mast cell degranulation than did PACAP-38, as reflected in changes in blood skin flow and wheal. Thus, flow and wheal are mediated via the VPAC receptors.

\section{HOW MIGHT PACAP-38 INDUCE MIGRAINE?}

At present, there is no firm evidence implicating the $\mathrm{PAC}_{1}$ receptor in migraine pathophysiology, and no $\mathrm{PAC}_{1}$ receptor antagonist is available for human use to test this hypothesis. Nonetheless, the ability of PACAP-38 to induce migraine, in contrast to VIP, strongly points to $\mathrm{PAC}_{1}$ receptor activation as a possible mediator of mi- graine. Experimental data noted in this review suggest that vasodilatation,,${ }^{10,33,35,36}$ mast cell degranulation, ${ }^{44,62}$ and neurogenic inflammation ${ }^{62}$ are induced by the VPAC receptors and therefore do not seem important in PACAP-38-induced migraine. Instead, PACAP-38 might modulate the $\mathrm{PAC}_{1}$ receptors at the second-order trigeminal neurons. After intravenous PACAP-38 administration, however, only $0.053 \%$ passes the blood-brain barrier (BBB) after 5 minutes via a saturable mechanism in mice. ${ }^{63}$ This suggests that activation of $\mathrm{PAC}_{1}$ receptors within the $\mathrm{BBB}$ is unlikely to mediate PACAP-38-induced migraine.

The most likely explanation for migraine development after administration of PACAP-38 seems to be modulation of dural or extracranial trigeminal nociceptors outside of the BBB. Thus, intracellular cAMP increase in dural nociceptors following $\mathrm{PAC}_{1}$ activation could be a necessary link in the cascade of events that leads to migraine development. Indeed, the headache-inducing effect of cilostazol, which is known to increase intracellular cAMP, has been tested; $92 \%$ of the healthy subjects developed headache, including $18 \%$ who had migrainelike features, such as pulsating pain quality and aggravation by physical activity. ${ }^{64}$ PACAP-38 and CGRP share the cAMP intracellular signaling pathway, and CGRP also does not pass the BBB freely. ${ }^{65}$ Intravenous infusion of CGRP induces migraine-like attacks occurring several hours after the end of the infusion, just as PACAP-38 induced migraine-like attacks, and the CGRP receptor antagonist telcagepant is effective for the acute treatment of migraine. ${ }^{66}$ Even though PACAP-38 most likely induces migraine through peripheral modulation, it is possible that a $\mathrm{PAC}_{1}$ receptor antagonist permeable to 
the BBB would have a synergetic dual effect at both first-order and second-order trigeminal neurons. $\mathrm{A} \mathrm{PAC}_{1}$ receptor antagonist is likely to be devoid of vascular side effects, which would be beneficial to migraine patients with ischemic vascular comorbidity.

Future studies should elucidate the possible pronociceptive effects of the $\mathrm{PAC}_{1}$ receptor. The development of a $\mathrm{PAC}_{1}$ receptor antagonist that can be tested in human clinical research would be extremely beneficial for our understanding of migraine mechanisms and possibilities for new treatments.

Acknowledgments: The present work was supported by the Lundbeck Foundation as part of the Lundbeck Foundation Center for Neurovascular Signalling (LUCENS).

\section{REFERENCES}

1. Andlin-Sobocki P, Jönsson B, Wittchen HU, Olesen J. Cost of disorders of the brain in Europe. Eur J Neurol 2005;12 Suppl $1: 1-27$.

2. Olesen J, Tfelt-Hansen P, Ashina M. Finding New drug targets for the treatment of migraine attacks. Cephalalgia 2009;29:909-920.

3. Olesen J, Burstein R, Ashina M, Tfelt-Hansen P. Origin of pain in migraine: evidence for peripheral sensitisation. Lancet Neurol 2009;8:679-690.

4. Uddman R, Tajti J, MÖller S, Sundler F, Edvinsson L. Neuronal messengers and peptide receptors in the human sphenopalatine and otic ganglia. Brain Res 1999;826:193-199.

5. Edvinsson L, Elsås T, Suzuki N, Shimizu T, Lee TJ. Origin and co-localization of nitric oxide synthase, CGRP, PACAP, and VIP in the cerebral circulation of the rat. Microsc Res Tech 2001;53: 221-228.

6. Nozaki K, Moskowitz MA, Maynard KI, et al. Possible origins and distribution of immunoreactive nitric oxide synthase-containing nerve fibers in cerebral arteries. J Cereb Blood Flow Metab 1993; 13:70-79.

7. Suzuki N, Hardebo JE. Anatomical basis for a parasympathetic and sensory innervation of the intracranial segment of the internal carotid artery in man: possible implication for vascular headache. J Neurol Sci 1991;104:19-31.

8. Lassen LH, Haderslev PA, Jacobsen VB, Iversen HK, Sperling B, Olesen J. CGRP may play a causative role in migraine. Cephalalgia 2002;22:54-61.

9. Thomsen LL, Kruuse C, Iversen HK, Olesen J. A nitric oxide donor triggers genuine migraine attacks. Eur J Neurol 1994;1: $73-80$.

10. Schytz HW, Birk S, Wienecke T, Kruuse C, Olesen J, Ashina M. PACAP38 induces migraine-like attacks in patients with migraine without aura. Brain 2009;132:16-25.

11. Miyata A, Arimura A, Dahl RR, et al. Isolation of a novel 38 residue-hypothalamic polypeptide which stimulates adenylate cyclase in pituitary cells. Biochem Biophys Res Commun 1989;164: 567-574.

12. Vaudry D, Falluel-Morel A, Bourgault S, et al. Pituitary adenylate cyclase-activating polypeptide and its receptors: 20 years after the discovery. Pharmacol Rev 2009;61:283-357.

13. Arimura A, Somogyvári-Vigh A, Miyata A, Mizuno K, Coy DH, Kitada C. Tissue distribution of PACAP as determined by RIA: highly abundant in the rat brain and testes. Endocrinology 1991; 129:2787-2789.

14. Ghatei MA, Takahashi K, Suzuki Y, Gardiner J, Jones PM, Bloom SR. Distribution, molecular characterization of pituitary adenylate cyclase-activating polypeptide and its precursor encoding messenger RNA in human and rat tissues. J Endocrinol 1993;136:159166.

15. Hannibal J, Mikkelsen JD, Clausen H, Holst JJ, Wulff BS, Fahrenkrug J. Gene expression of pituitary adenylate cyclase activating polypeptide (PACAP) in the rat hypothalamus. Regul Pept 1995;55:133-148.

16. Mikkelsen JD, Hannibal J, Fahrenkrug J, Larsen PJ, Olcese J, McArdle C. Pituitary adenylate cyclase activating peptide-38 (PACAP-38), PACAP-27, and PACAP related peptide (PRP) in the rat median eminence and pituitary. J Neuroendocrinol 1995;7: $47-55$.

17. Tajti J, Uddman R, Möller S, Sundler F, Edvinsson L. Messenger molecules and receptor mRNA in the human trigeminal ganglion. J Auton Nerv Syst 1999;76:176-183.

18. Uddman R, Tajti J, Hou M, Sundler F, Edvinsson L. Neuropeptide expression in the human trigeminal nucleus caudalis and in the cervical spinal cord C1 and C2. Cephalalgia 2002;22:112-116.

19. Vaudry D, Gonzalez BJ, Basille M, Yon L, Fournier A, Vaudry H. Pituitary adenylate cyclase-activating polypeptide and its receptors: from structure to functions. Pharmacol Rev 2000;52:269324 .

20. Mulder H, Uddman R, Moller K, et al. Pituitary adenylate cyclase activating polypeptide is expressed in autonomic neurons. Regul Pept 1995;59:121-128.

21. Harmar AJ, Arimura A, Gozes I, et al. International Union of Pharmacology. XVIII. Nomenclature of receptors for vasoactive intestinal peptide and pituitary adenylate cyclase-activating polypeptide. Pharmacol Rev 1998;50:265-270.

22. Dickson L, Finlayson K. VPAC and PAC receptors: from ligands to function. Pharmacol Ther 2009;121:294-316.

23. Dickinson T, Fleetwood-Walker SM. VIP and PACAP: very important in pain? Trends Pharmacol Sci 1999;20:324-329.

24. Knutsson M, Edvinsson L. Distribution of mRNA for VIP and PACAP receptors in human cerebral arteries and cranial ganglia. Neuroreport 2002;13:507-509.

25. Zagami AS, Edvinsson L, L. HK, Goadsby PJ. Stimulation of the superior sagittal sinus causes extracranial release of PACAP. Cephalalgia 1995;15(Suppl 14):109.

26. Yarnitsky D, Goor-Aryeh I, Bajwa ZH, et al. 2003 Wolff Award: Possible parasympathetic contributions to peripheral and central sensitization during migraine. Headache 2003;43:704-714.

27. Maizels M, Scott B, Cohen W, Chen W. Intranasal lidocaine for treatment of migraine: a randomized, double-blind, controlled trial. JAMA 1996;276:319-321.

28. Rozniecki JJ, Dimitriadou V, Lambracht-Hall M, Pang X, Theoharides TC. Morphological and functional demonstration of rat dura mater mast cell-neuron interactions in vitro and in vivo. Brain Res 1999;849:1-15.

29. Iversen HK, Nielsen TH, Olesen J, Tfelt-Hansen P. Arterial responses during migraine headache. Lancet 1990;336:837-839.

30. Friberg L, Olesen J, Iversen HK, Sperling B. Migraine pain associated with middle cerebral artery dilatation: reversal by sumatriptan. Lancet 1991;338:13-17.

31. Uddman R, Goadsby PJ, Jansen I, Edvinsson L. PACAP, a VIPlike peptide: immunohistochemical localization and effect upon cat pial arteries and cerebral blood flow. J Cereb Blood Flow Metab 1993;13:291-297.

32. Seki Y, Suzuki Y, Baskaya MK, et al. The effects of pituitary adenylate cyclase-activating polypeptide on cerebral arteries and vertebral artery blood flow in anesthetized dogs. Eur J Pharmacol 1995;275:259-266.

33. Boni LJ, Ploug KB, Olesen J, Jansen-Olesen I, Gupta S. The in vivo effect of VIP, PACAP-38 and PACAP-27 and mRNA expression of their receptors in rat middle meningeal artery. Cephalalgia 2009;29:837-847.

34. Birk S, Sitarz JT, Petersen KA, et al. The effect of intravenous PACAP38 on cerebral hemodynamics in healthy volunteers. Regul Pept 2007;140:185-191.

35. Baun M, Olesen J, Jansen-Olesen I. Expression studies and pharmacological characterization of VIP and PACAP receptors in the cerebral circulation of the rat. Cephalalgia 2009;29 Suppl 1:133 (abstract PO316).

36. Baun M, Chan KY, Olesen J, Jansen-Olesen I, Gupta S, Maassen Van Den Brink A. Pharmacological characterization and mRNA expression studies of VIP and PACAP receptors in human coronary arteries. Cephalalgia 2009;29 Suppl 1:132 (abstract PO315). 
37. Levy D. Migraine pain, meningeal inflammation, and mast cells. Curr Pain Headache Rep 2009;13:237-240.

38. Theoharides TC, Donelan J, Kandere-Grzybowska K, Konstantinidou A. The role of mast cells in migraine pathophysiology. Brain Res Brain Res Rev 2005;49:65-76.

39. Heatley RV, Denburg JA, Bayer N, Bienenstock J. Increased plasma histamine levels in migraine patients. Clin Allergy 1982; 12:145-149.

40. Lassen LH, Thomsen LL, Olesen J. Histamine induces migraine via the H1-receptor. Support for the NO hypothesis of migraine. Neuroreport 1995;6:1475-1479.

41. Levy D, Burstein R, Kainz V, Jakubowski M, Strassman AM. Mast cell degranulation activates a pain pathway underlying migraine headache. Pain 2007;130:166-176.

42. Zhang XC, Strassman AM, Burstein R, Levy D. Sensitization and activation of intracranial meningeal nociceptors by mast cell mediators. J Pharmacol Exp Ther 2007;322:806-812.

43. Kulka M, Sheen CH, Tancowny BP, Grammer LC, Schleimer RP. Neuropeptides activate human mast cell degranulation and chemokine production. Immunology 2008;123:398-410.

44. Odum L, Petersen LJ, Skov PS, Ebskov LB. Pituitary adenylate cyclase activating polypeptide (PACAP) is localized in human dermal neurons and causes histamine release from skin mast cells. Inflamm Res 1998;47:488-492.

45. Ottosson A, Edvinsson L. Release of histamine from dural mast cells by substance $\mathrm{P}$ and calcitonin gene-related peptide. Cephalalgia 1997;17:166-174.

46. Dickson L, Aramori I, McCulloch J, Sharkey J, Finlayson K. A systematic comparison of intracellular cyclic AMP and calcium signalling highlights complexities in human VPAC/PAC receptor pharmacology. Neuropharmacology 2006;51:1086-1098.

47. Levy D, Strassman AM. Distinct sensitizing effects of the cAMPPKA second messenger cascade on rat dural mechanonociceptors. J Physiol 2002;538:483-493.

48. Ingram SL, Williams JT. Modulation of the hyperpolarizationactivated current (Ih) by cyclic nucleotides in guinea-pig primary afferent neurons. J Physiol 1996;492(Pt 1):97-106.

49. Akerman S, Goadsby PJ. VPAC 1 and $\mathrm{PAC}_{1}$ receptor antagonists inhibit activation of the parasympathetic outflow to the cranial vasculature to prevent autonomic responses and neuronal firing in the trigeminocervical complex. Cephalalgia 2009;29 Suppl 1:130 (abstract PO310).

50. Tajti J, Uddman R, Edvinsson L. Neuropeptide localization in the "migraine generator" region of the human brainstem. Cephalalgia 2001;21:96-101.

51. Basbaum AI, Clanton CH, Fields HL. Three bulbospinal pathways from the rostral medulla of the cat: an autoradiographic study of pain modulating systems. J Comp Neurol 1978;178:209-224.

52. Weiller C, May A, Limmroth V, et al. Brain stem activation in spontaneous human migraine attacks. Nat Med 1995;1:658-660.

53. Hashimoto H, Shintani N, Baba A. New insights into the central
PACAPergic system from the phenotypes in PACAP- and PACAP receptor-knockout mice. Ann N Y Acad Sci 2006;1070:75-89.

54. Zhang Y, Malmberg AB, Yaksh TL, Sjölund B, Sundler F, Håkanson R. Capsaicin-evoked release of pituitary adenylate cyclase activating peptide (PACAP) and calcitonin gene-related peptide (CGRP) from rat spinal cord in vivo. Regul Pept 1997;69:83-87.

55. Mabuchi T, Shintani N, Matsumura S, et al. Pituitary adenylate cyclase-activating polypeptide is required for the development of spinal sensitization and induction of neuropathic pain. J Neurosci 2004;24:7283-7291.

56. Ji RR, Kohno T, Moore KA, Woolf CJ. Central sensitization and LTP: do pain and memory share similar mechanisms? Trends Neurosci 2003;26:696-705.

57. Jongsma H, Pettersson LM, Zhang YZ, et al. Markedly reduced chronic nociceptive response in mice lacking the $\mathrm{PAC}_{1}$ receptor. Neuroreport 2001;12:2215-2219.

58. Davis-Taber R, Baker S, Lehto SG, et al. Central pituitary adenylate cyclase 1 receptors modulate nociceptive behaviors in both inflammatory and neuropathic pain states. J Pain 2008;9:449-456.

59. Ohsawa M, Brailoiu GC, Shiraki M, Dun NJ, Paul K, Tseng LF. Modulation of nociceptive transmission by pituitary adenylate cyclase activating polypeptide in the spinal cord of the mouse. Pain 2002;100:27-34.

60. Hansen JM, Sitarz J, Birk S, et al. Vasoactive intestinal polypeptide evokes only a minimal headache in healthy volunteers. Cephalalgia 2006;26:992-1003.

61. Rahmann A, Wienecke T, Hansen JM, Fahrenkrug J, Olesen J, Ashina M. Vasoactive intestinal peptide causes marked cephalic vasodilation, but does not induce migraine. Cephalalgia 2008;28: 226-236.

62. Schytz HW, Holst H, Arendt-Nielsen L, Olesen L, Ashina M. Cutaneous nociception and neurogenic inflammation evoked by VIP and PACAP38: a human experimental study. Cephalalgia 2009;29(12):1358 (abstract LBPO08).

63. Banks WA, Kastin AJ, Komaki G, Arimura A. Passage of pituitary adenylate cyclase activating polypeptide 1-27 and pituitary adenylate cyclase activating polypeptide1-38 across the blood-brain barrier. J Pharmacol Exp Ther 1993;267:690-696.

64. Birk S, Kruuse C, Petersen KA, Tfelt-Hansen P, Olesen J. The headache-inducing effect of cilostazol in human volunteers. Cephalalgia 2006;26:1304-1309.

65. Edvinsson L, Nilsson E, Jansen-Olesen I. Inhibitory effect of BIBN4096BS, CGRP ${ }_{8-37}$, a CGRP antibody and an RNASpiegelmer on CGRP induced vasodilatation in the perfused and non-perfused rat middle cerebral artery. Br J Pharmacol 2007;150: 633-640.

66. Ho TW, Mannix LK, Fan X, et al.; MK-0974 Protocol 004 Study Group. Randomized controlled trial of an oral CGRP receptor antagonist, MK-0974, in acute treatment of migraine. Neurology 2008;70:1304-1312. 